\title{
Geophysics: ins and outs of the library
}

\section{Jean-Claude De Bremaecker}

\author{
Annales Geophysicae. Editor-in-chief Stephan Mueller. \\ Gauthier-Villars, 11 rue Gossin, F-92543 Montrouge Cedex, France. \\ 6/yr. FF780.
}

First Break. Editor Ian Williamson.

Blackwell Scientific. 12/yr. £34.50, \$58.

GEOPHYSICALLY, Europe is slowly emerging from the deep: she wears a Latin dress but speaks English. At least, so it seems, for Annales Geophysicae (AG) has replaced both the French Annales de Géophysique and the Italian Annali di Geofisica.

As the official journal of the European Geophysical Society, the future of the journal is promising. It embraces the same subjects as its well-known American counterpart, the Journal of Geophysical Research; that is, all the fields covered by the International Union of Geodesy and Geophysics, but with one confusing exception: geochemistry and volcanology are not mentioned in the "scope of the journal". It appears that geodesy may also be excluded, but this is less certain. Further to confuse matters, the president of the EGS states in the first issue that volcanology and geochemistry as well as geodesy are included. The "scope" appears inside the front cover, the president's words on the facing right-hand page, and never have the twain met.

One presumes that all articles are refereed, and very speedily too, since the average delay for acceptance is about two months. The editorial board is made up exclusively of western European geophysicists, and very few contributors come from eastern Europe either, a geographical bias which should be corrected. The articles are of a remarkably high quality for a new publication, the abstracts not always so. Thirty-three years have passed since Kenneth Landes's classical "Scrutiny of the Abstract" (Bull. Am. Ass. petrol. Geol. 35, 1660) yet still one finds that "The theory....is developed. An algorithm ... is proposed. Examples... are presented. The possibility of application...is discussed". It seems only reasonable to hope that the editors will in future demand abstracts that are, in Landes's words, "a condensation of the essential qualities of the paper" and " not a mere recital of the subjects covered".

English, we all know, is a good simple international language (except for its spelling). As a non-native speaker residing in the United States, I particularly appreciate the problems which AG's authors and editors have faced and generally overcome. A simple example comes to mind: the French "Pour lever cette difficulté..." does not mean "in order to raise the difficulty". There are very few such examples in the journal, and perhaps the best solution to this problem is to forget it; for, as scientists say, "the solution is not entirely clear", which means that it is utterly obscure.

One attractive feature of $A G$ is the absence of page charges, coupled with the supply of 50 free reprints. The format (twocolumn on approximately $21 \times 30 \mathrm{~cm}$ paper) is open and pleasant, the printing is of high quality, while the style and typography for the references are the best that I have ever come across. Much as in the Journal of Geophysical Research, only articles are published, but short notes are also welcome. So far no "comments" on previously published papers have appeared; presumably they will, eventually. Overall, at a subscription price of FF780 (c. \$84) outside France, this is a bargain that libraries should not miss.

First Break (FB) is a different sort of beast. It does not aim at being a scientific journal, instead publishing "short nontechnical articles...and up-to-date news about the geophysics industry". It is thus not meant to be archived, but does fill a clear need by offering executives and others in the oil industry a means of keeping abreast of events. The industry news consists mostly of publicity releases, and has to be read with a dose of scepticism - that does not make it less valuable. It thus goes without saying that few libraries will want to subscribe to $F B$, which is to the good of everybody concerned.

The editor is to be commended for dealing exclusively with items connected with geophysics. This may seem obvious, but it is not. Only a little while back its counter-

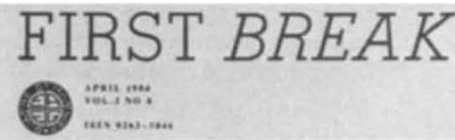

part in the United States, The Leading Edge, was launched and unwisely included anything of conceivable interest to geophysicists. As a result its first numbers contained a mish-mash of right-wing propaganda, cross-word puzzles and sports news, with a dash of geophysics added for good measure. First Break, it seems, has profited from that sad example.

A common temptation with a publication such as this is for the publishers to try to "upgrade" it to a bona fide scientific journal. This shoal has not been avoided entirely by FB: at least one paper is reproduced from a well-known geophysical journal. Worse yet would be to fall to the level of taking non-refereed papers which have not been accepted (and could not be) by established journals - far better to publish a slimmer issue than one containing second-rate material. One can only hope that the editor will keep his goal firmly in mind over the next few years; some of the papers are a little disquieting in this respect.

First Break is a readable, informative and reasonably cheap publication. But considering the world-wide scope of the geophysics industry and its currently rather depressed state, as well as the thinness of both FB and The Leading Edge, I cannot help but wonder whether these two publications should not merge. It might bruise some editorial egos but the readers of both might well be better served.

Jean-Claude De Bremaecker is a Professor of Geophysics at Rice University, Texas.

\section{Talk of integration and communication}

John Tarney

Journal of Metamorphic Geology.

Editors M. Brown, T.P. Loomis and

R.H. Vernon.

Blackwell Scientific. 4/yr.

£47, \$97.50.

Geochemistry.

Chairman of the editorial committee Tu

Guangchi.

Science Press, Beijing/Springer-Verlag.

4/yr. DM 129, \$54.50.

IT woulD not be exaggerating to say that well over half of the Earth's continental crust is composed of metamorphic rocks, so it is surprising that there has been no specific journal acting as a focal point for research in this area. Until now, observational details have been recorded separately in various national and international journals of mineralogy, petrology, geochemistry or structural geology, of which there are now a great many, and this has put limitations on the possibilities for an integrated approach to the subject.

The new Journal of Metamorphic Geology (JMG), titled as it is with the broad term "geology" rather than just "petrology" and so on, should provide an appropriate vehicle for the reporting of broader ranging research on metamorphic rocks, although this may be more commonly achieved through the publication of thematic issues. Certainly, detailed integrated studies are now beginning to tell us a great deal about the past thermal and tectonic histories of metamorphic rocks, and the importance of fluids, which may be of great value in attempts to reconstruct the geological evolution of a province in terms, for instance, of plate tectonics.

During its first year, JMG has attracted 